УДК 542.06

\title{
ИЗВЛЕЧЕНИЕ ФЛАВОНОИДОВ ИЗ ГОРЯНКИ КОРОТКОНОЖКОВОЙ (EPIMEDIUM BREVICORNUM L.) В CРЕДЕ СВЕРХКРИТИЧЕСКОГО ДИОКСИДА УГЛЕРОДА
}

\author{
(C) О.А. Шевлякова ${ }^{*}$, К.Ю. Васильев ${ }^{1}$, А.А. Ихалайнен ${ }^{1}$, А.М. Антохин ${ }^{1}$, В.Ф. Таранченко \\ В.М. Гончаров ${ }^{1}$, А.В. Аксенов ${ }^{1}$, Д.А. Митрофанов ${ }^{1}$, И.А. Родин ${ }^{2}$, О.А. Шиигун \\ ${ }^{1}$ Научный центр «Сигнал», ул. Большая Оленья, 8, Москва, 107014 (Россия), \\ e-mail: olesya.shevlyakova@gmail.com \\ ${ }^{2}$ Московский государственный университет им. М.В. Ломоносова, \\ химический фракультет, Ленинские горы, 1-3, Москва, 119991 (Россия)
}

Рассмотрены достоинства сверхкритической экстракции по сравнению с другими способами извлечения активных компонентов из растительного сырья. Показана перспективность применения экстракции сверхкритическим диоксидом углерода биологически активных соединений из листьев горянки коротконожковой (Epimedium Brevicornum L.). Исследована зависимость степени извлечения флавоноидов от параметров экстракции (температуры, давления, времени). Установлено, что максимальный выход действующих компонентов достигается при температуре $50{ }^{\circ} \mathrm{C}$, давлении 30 МПа и продолжительности 30 мин. С использованием метода жидкостной хроматографии/масс-спектрометрии проведена сравнительная оценка количественного содержания икариина, икаризида II, эпимединов А, В, С в экстрактах листьев горянки коротконожковой, полученных методом экстракции сверхкритическим диоксидом углерода и жидкостной экстракцией с применением ультразвука. Предложенный нами метод превосходит традиционную жидкостную экстракцию с применением ультразвука в 2,5 раза.

Ключевые слова: горянка коротконожковая, сверхкритическая экстракция диоксидом углерода, икариин, икаризид II, эпимедин А, В, С, высокоэффективная жидкостная хроматография, масс-спектрометрия.

\section{Введение}

Горянка (лат. Epimedium) — род многолетних травянистых растений семейства Барбарисовые. Сегодня насчитывается более 60 видов, встречающихся в Восточном полушарии (предгорья Европы, Кавказа, Турции, Японии и Китая) $[1,2]$. Несмотря на широкое распространение видов горянки в медицинской практике используются лишь немногие. Согласно китайской фармакопее [3], высушенные надземные части Epimedium brevicornum Maxim., Epimedium sagittatum Maxim., Epimedium pubescens Maxim., Epimedium wushanense T.S. Ying и Epimedium koreanum Nakai содержат наиболее высокие концентрации флавоноидов, которые являются важнейшими функционально значимыми соединениями, присутствующими в растении, и обладают биологической активностью: противоопухолевой, андрогенной, антидепрессантной, антиостеопорозной и иммуномодуляционной [4-12].

Очевидно, что от технологий извлечения биологически активных веществ из лекарственных растений зависит качество фармпрепаратов, создаваемых на их основе (содержание и соотношение основных

Шевлякова Олеся Александровна - научный сотрудник, e-mail: olesya.shevlyakova@gmail.com

Васильев Кирилл Юрьевич - ведущий консультант, e-mail: info@ncsignal.ru

Ихалайнен Андрей Александрович - ведущий научный сотрудник, доктор биологических наук, доцент, e-mail: an12321na@gmail.com физиологически активных компонентов), а также эффективность действия. Изучению экстракции действующих компонентов горянки посвящено множество работ. Однако в большинстве своем все они сводятся к выделению основных компонентов традиционными органическими растворителями в различных условиях [13-17]. Эти техно-

\footnotetext{
* Автор, с которым следует вести переписку.
} 
логии имеют ряд недостатков, основным из которых является необходимость удаления растворителя из экстракта. В связи с этим становится актуальной задача освоения новых, высокотехнологичных, экологичных и перспективных методов, способных повысить эффективность переработки ценного растительного сырья. К их числу относится экстракция растворителями, находящимися в сверхкритическом состоянии, в том числе диоксидом углерода. Сверхкритическая экстракция обладает рядом преимуществ по сравнению с другими способами извлечения: обеспечиваются экологичность, быстрота процесса, высокий выход конечного продукта; низкая температура экстракции; исключается проблема остаточного растворителя в экстракте; процесс экстракции протекает без контакта с кислородом воздуха, что позволяет экстрагировать оксилабильные соединения [18-21].

Однако в настоящее время в печати отсутствуют сведения, посвященные исследованиям выделения активных компонентов из горянки с использованием экстракции сверхкритическим $\mathrm{CO}_{2}\left(\mathrm{CK}_{-} \mathrm{CO}_{2}\right)$. Поэтому целью настоящей работы являлось исследование возможности применения экстракции сверхкритическим диоксидом углерода для выделения флавоноидов из горянки, а также сравнительная оценка количественного содержания активных компонентов в экстрактах, полученных извлечением в среде сверхкритического диоксида углерода и методом жидкостной экстракции.

\section{Экспериментальная часть}

Объектом нашего исследования являются листья коротконожковой горянки (Epimedium brevicornum), собранные на востоке Китая и высушенные в тени в проветриваемом помещении при температуре $35-38{ }^{\circ} \mathrm{C}$. В рамках данной работы внимание было уделено пяти флавоноидам, входящим в состав данного лекарственного растения: икариину, икаризиду II, эпимединам А, В, С (табл.).

Экстракцию сверхкритическим диоксидом углерода проводили на лабораторной установке производства компании Waters Corporation, США, модели SFE-100.

Для экстракции основных компонентов горянки использовали листья Epimedium brevicornum из одной партии лекарственного растительного сырья. Листья горянки измельчали до 6-8 мм, отбирали 5,0 г и экстрагировали при температурах от 40 до $60^{\circ} \mathrm{C}$ с шагом $5{ }^{\circ} \mathrm{C}$ и давлениях от 10 до 30 МПа с шагом 5 МПа в течение 15, 30 и 45 мин. В качестве сорастворителя использовали $80 \%$ этанол. Скорости подачи со-растворителя и углекислого газа составляли 3 и 7 г/мин, соответственно.

Для сравнительной оценки эффективности экстракции сверхкритическим диоксидом углерода были также получены спиртовые экстракты ультразвуковым методом с использованием оптимизированных параметров, приведенных в работе [22]. К 1 г измельченного сырья добавляли 30 мл экстрагента (50\% раствор этанола в воде). Смесь выдерживали в ультразвуковой бане при $50{ }^{\circ} \mathrm{C}$ в течение 30 мин. После этого отбирали 1 мл экстракта, центрифугировали 12 мин при 16000 об мин ${ }^{-1}$, пропускали через бумажный фильтр с размером пор 0,45 мкм фирмы Macherey-Nagel и исследовали методом ВЭЖХ с массспектральной детекцией. Проводили три последовательных этанольных экстракции.

Количественный анализ полученных экстрактов осуществляли на высокоэффективном жидкостном

Антохин Андрей Михайлович - заместитель директора, кандидат технических наук, доцент, e-mail: antohin_08@mail.ru

Таранченко Виктор Федорович - начальник отдела, кандидат химических наук, доцент,

e-mail: victaran@rambler.ru

Гончаров Валерий Михайлович - ведущий научный сотрудник, кандидат химических наук, доцент, e-mail: GVM52005@ya.ru

Аксенов Алексей Вадимович - заведующий лабораторией, кандидат технических наук, доцент,

e-mail: aksenov_av@list.ru

Митрофанов Дмитрий Александрович - ведущий научный сотрудник, кандидат химических наук, доцент,

e-mail: lab-tex@mail.ru

Родин Игорь Александрович - старший научный сотрудник кафедры аналитической химии, кандидат химических наук, e-mail: igorrodin@ya.ru

Шпигун Олег Алексеевич - профессор кафедры аналитической химии, член-корр. РАН, доктор химических наук, e-mail: shpigun@analyt.chem.msu.ru хроматографе Dionex Ultimate 3000 RS, оснащенном автосамплером, градиентным насосом, дегазатором и блоком для термостатирования хроматографической колонки, соединенном с гибридным масс-спектрометром QExactive с орбитальной ионной ловушкой высокого разрешения (Thermo Scientific, Германия) и источником ионизации IonMax HESI-II. В качестве распыляющего и вспомогательного газа использовали азот от генератора азота Genius 1022 (Peak Scientific, Англия). Детектирование осуществляли в диапазоне масс 100 1550 Да при регистрации положительных ионов с разрешением 35000 (на половине высоты) и точностью определения масс 5 млн $^{-1}$. Обработку данных проводили с применением программного обеспечения XCalibur версии 2.2 (Thermo Scientific, США). 
Структурные формулы основных флавоноидов горянки

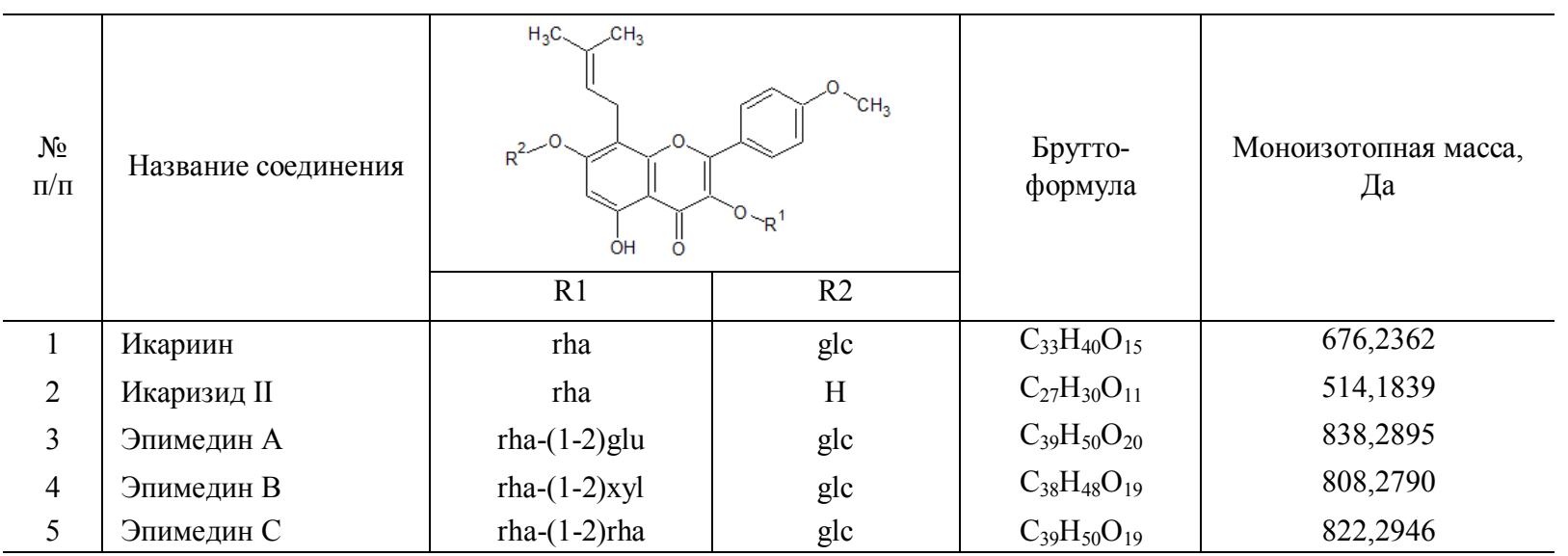

Примечание: rha - рамнозил, glc - глюкозил, xyl - ксилозил.

При определении флавоноидов использовали колонку с обращенно-фазовым сорбентом Hypersil Gold aQ, длиной 150 мм, внутренним диаметром 2,1 мм, размером зерна сорбента 3 мкм, фирмы Тhеrто Scientific. Температура колонки составляла $45^{\circ} \mathrm{C}$, объемная скорость потока подвижной фазы - 0,6 мл мин ${ }^{1}$. В качестве подвижной фазы использовали 0,1\% раствор муравьиной кислоты в смеси ацетонитрил/вода в соотношении 5 : 95 (об.) (А) и 0,1\% раствор муравьиной кислоты в ацетонитриле (В). Хроматографическое разделение веществ проводили в режиме градиентного элюирования: 0-1 мин - 20\% В; 4 мин - 25\% В; 4,5 мин - 40\% В; 7,5 мин - 95\% В; 7,5-10,5 мин - 95\% В; 11 мин - 20\% В. Время анализа с учетом стабилизации системы перед вводом следующего образца составляло 15 мин. Объем вводимой пробы - 0,005 мл.

Количественный анализ флавоноидов проводили методом внешних стандартов. Построение градуировочных зависимостей (площади хроматографического пика вещества от его концентрации) осуществляли с использованием стандартных образцов икариина, икаризида II, эпимединов A, B, C (>98\%, Phytolab, Германия). Навески флавоноидов массой 1 мг растворяли в 1 мл метанола. Полученные растворы использовали для построения градуировочных зависимостей в диапазоне концентраций 0,0005-200 мкг/мл ${ }^{-1}$ по каждому из изучаемых компонентов.

\section{Обсуждение результатов}

Основными параметрами, влияющими на эффективность экстракции, являются ее продолжительность, давление и температура. Влияние данных параметров на общее количество извлекаемых флавоноидов показано на рисунках 1,2 .

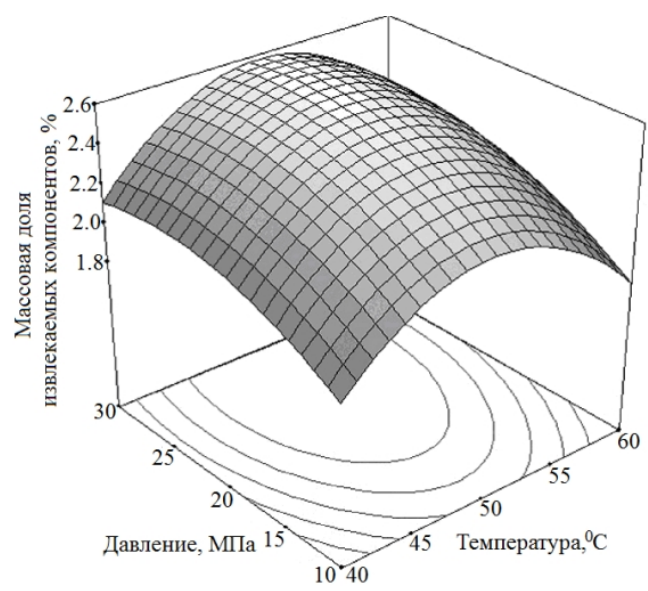

Рис. 1. 3D-график зависимости суммарной массовой доли извлекаемых флавоноидов (\%) от давления и температуры при времени экстракции 30 мин

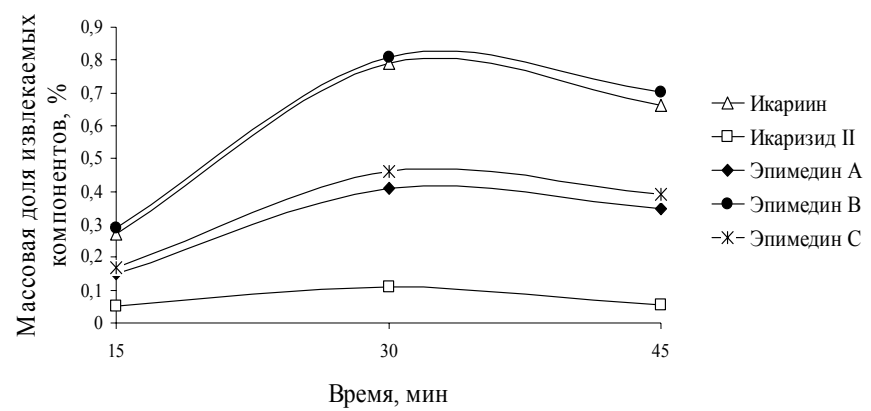

Рис. 2. Выход целевых компонентов при различном времени экстракции 
Зависимость на рисунке 1 показывает, что с увеличением давления наблюдается повышение суммарного выхода флавоноидов с достижением его максимального значения при величине 30 МПа на уровне $2,6 \%$ от массы экстрагируемого сырья. Эффективность экстракции достигает максимального значения при температуре $50^{\circ} \mathrm{C}$. Снижение или повышение температуры приводит к уменьшению выхода целевых компонентов.

Проанализировав данные рисунка 2, делаем вывод, что в качестве оптимального времени экстракции можно принять 30 мин. Дальнейшее увеличение продолжительности процесса приводит к потерям целевых компонентов, а также к дополнительным экономическим затратам (в том числе на сорастворитель и сверхкритический $\left.\mathrm{CO}_{2}\right)$.

Для оценки эффективности метода $\mathrm{CK}-\mathrm{CO}_{2}$ было проведено сравнение его с традиционным методом жидкостной экстракции 50\% этанолом под действием ультразвука.

На рисунке 3 представлена диаграмма, показывающая количество извлекаемых биологически активных соединений при использовании различных методов экстракции.

Из представленных данных видно, что суммарное количество извлекаемых компонентов методом $\mathrm{CK}-\mathrm{CO}_{2}$ при температуре $50{ }^{\circ} \mathrm{C}$, давлении 30 МПа и продолжительности 30 мин в 2,5 раза выше, чем с помощью жидкостной экстракции этанолом под действием ультразвука.

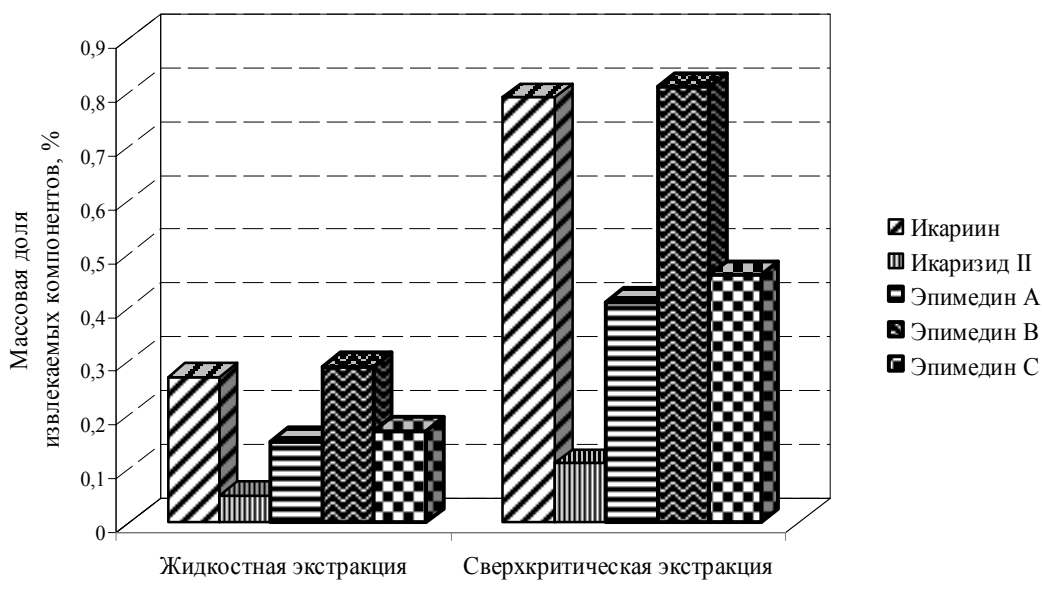

Рис. 3. Выход извлекаемых компонентов при использовании различных методов экстракции

\section{Bы6odbl}

Таким образом, нами показана принципиальная возможность применения экстракции сверхкритическим диоксидом углерода для извлечения флавоноидов из горянки коротконожковой (Epimedium Brevicornum). Предложенный нами метод превосходит традиционную жидкостную экстракцию с применением ультразвука в 2,5 раза. Варьирование параметров экстракции позволяет регулировать выход целевых веществ. Установлено, что максимальный выход действующих компонентов достигается при температуре $50{ }^{\circ} \mathrm{C}$, давлении 30 МПа и продолжительности 30 мин.

\section{Список литературь}

1. Флора СССР. М., 1937. Т. 7. 718 c.

2. Энциклопедический словарь Ф.А. Брокгауза и И.А. Ефрона: Бесцветник. СПб., 1980. Т. ЗА. №6. 956 с.

3. Editorial Committee of Pharmacopoeia of Ministry of Health PR China, The Pharmacopoeia of People's Republic of China. Beijing, 2010. Vol. 1.

4. Huang X., Zhu D.Y., Lou Y.J. A novel anticancer agent, icaritin, induced cell growth inhibition, G1 arrest and mitochondrial transmembrane potential drop in human prostate carcinoma PC-3 cells // Eur. J. Pharmacol. 2007. Vol. 564, N1-3. Pp. 26-36.

5. Humfrey C.D. Phytoestrogens and human health effects: weighing up the current evidence // Nat. Toxins. 1998. Vol. 6, N2. Pp. 51-59.

6. Felson D.T., Zhang Y., Hannan M.T., Kiel D.P., Wilson P.W., Anderson J.J. The effect of postmenopausal estrogen therapy on bone density in elderly women // N. Engl. J. Med. 1993. Vol. 329, N16. Pp. 1141-1146.

7. Pan Y., Kong L., Xia X., Zhang W., Xia Z., Jiang F. Antidepressant-like effect of icariin and its possible mechanism in mice // Pharmacol. Biochem. Behav. 2005. Vol. 82, N4. Pp. 686-694.

8. Wu J., Du J., Xu C., Le J., Xu Y., Liu B., Dong B. Icariin attenuates social defeat-induced down-regulation of glucocorticoid receptor in mice // Pharmacol. Biochem. Behav. 2011. Vol. 98, N2. Pp. 273-278. 
9. Ji H., Liu K., Li S.P., Gong X.J. Effect of HEF on osteoporosis induced by retinoic acid in male rats // J. Chin. Pharm. Univ. 2000. Vol. 31, N3. Pp. 222-225.

10. Meng F., Li Y.B., Xiong Z.L., Jiang Z.M., Li F.M. Osteoblastic proliferative activity of Epimedium brevicornum Maxim. // Phytomedicine. 2005. Vol. 12, N3. Pp. 189-193.

11. Ma A., Qi S., Xu D., Zhang X., Daloze P., Chen H. Baohuoside-1, a novel immunosuppressive molecule, inhibits lymphocyte activation in vitro and in vivo // Transplantation. 2004. Vol. 78, N6. Pp. 831-838.

12. Cai M.L., Ji H., Li P., Wang M.Q. Effects of five flavonoids isolated from Epimedium pubescens on osteoblasts in vitro // Chin. J. Nat. Med. 2004. Vol. 2, N4. Pp. 235-238.

13. Wang Y., Guo Z., Jin Y., Zhang X., Wang L., Xue X., Liang X. Identification of prenyl flavonoid glycosides and phenolic acids in Epimedium koreanum Nakai by Q-TOF-MS combined with selective enrichment on «click oligo (ethylene glycol)» column // J. Pharm. and Biomed. Anal. 2010. Vol. 51, N3. Pp. 606-616.

14. Wu C.S., Guo B.L., Sheng Y.X., Zhang J.L. Simultaneous determination of seven flavonoids in Epimedium by liquid chromatography-tandem mass spectrometry method // Chinese Chemical Letters. 2008. Vol. 19. Pp. 329-332.

15. Chen X.J., Ji H., Zhang Q.W., Tu P.F., Wang Y.T., Guo B.L., Li S.P. A rapid method for simultaneous determination of 15 flavonoids in Epimedium using pressurized liquid extraction and ultra-performance liquid chromatography // J. Pharm. and Biomed. Anal. 2008. Vol. 46, N2. Pp. 226-235.

16. Xu Y., Li Z., Yuan L., Zhang X., Lu D., Huang H., Wang Y. Variation of Epimedins A - C and Icariin in Ten Representative Populations of Epimedium brevicornu Maxim., and Implications for Utilization // Chemistry and Biodiversity. 2013. Vol. 10, N4. Pp. 711-721.

17. Li Y., Duan J., Guo T., Xie W., Yan S., Li B., Zhou Y., Chen Y. In vivo pharmacokinetics comparisons of icariin, emodin and psoralen from gan-kang granules and extracts of herba Epimedii, Nepal dock root, Ficus hirta yahl // J. Ethnopharmacol. 2009. Vol. 124, N3. Pp. 522-529.

18. Могилюк В., Добровольный А. Сверхкритическая флюидная экстракция растительного сырья: перспективная технологическая платформа для фармацевтической промышленности // Фармацевтическая отрасль. 2015. Т. 48, №1. С. $62-68$.

19. Покровский О. Пробоподготовка в химическом анализе методом сверхкритической флюидной экстракции // Аналитика. 2013. Т. 6, №13. С. 22-27.

20. Боголицын К.Г. Перспективы применения сверхкритических флюидных технологий в химии растительного сырья // Сверхкритические Флюиды: Теория и Практика. 2007. Т. 2, №1. С. 16-27.

21. Водяник А.Р., Шадрин А.Ю., Синев М.Ю. Сверхкритическая флюидная экстракция природного сырья: мировой опыт и ситуация в России // Сверхкритические Флюиды: Теория и Практика. 2008. Т. 3, №2. С. 58-69.

22. Zhang H.-F., Yang T.-S., Li Z.-Z., Wang Y. Simultaneous extraction of epimedin A, B, C and icariin from Herba Epimedii by ultrasonic technique// Ultrasonics Sonochemistry. 2008. Vol. 15, N4. Pp. 376-385.

Поступило в редакииюю 25 мая 2015 г. 
Shevlyakova O.A. ${ }^{1 *}$, Vasil'yev K.Ju. ${ }^{l}$, Ihalaynen A.A. ${ }^{l}$, Antokhin A.M. ${ }^{l}$, Taranchenko V.F. ${ }^{l}$, Goncharov V.M. ${ }^{l}$, Aksenov A.V. ${ }^{l}$, Mitrofanov D.A. ${ }^{l}$, Rodin I.A. ${ }^{2}$, Shpigun O.A. ${ }^{2}$ EXTRACTION OF FLAVONOIDS FROM EPIMEDIUM BREVICORNUM USING SUPERCRITICAL CARBON DIOXIDE

${ }^{\text {I} F e d e r a l ~ S t a t e ~ U n i t a r y ~ E n t e r p r i s e ~ " S c i e n t i f i c ~ C e n t e r ~ " S i g n a l ”, ~ B o l s h a y a ~ O l e n y a, ~ 8, ~ M o s c o w, ~} 107014$ (Russia), e-mail: olesya.shevlyakova@gmail.com

${ }^{2}$ Chemistry Department, Lomonosov Moscow State University, Leninskie gory, 1-3, Moscow, 119991 (Russia)

Advantages of supercritical extraction in comparison with other extract methods for active components from plant materials were discussed. The possibility of utilization of extraction with supercritical carbon dioxide for the isolation of biologically active substances from the leaves of Epimedium Brevicornum was demonstrated. The dependence of efficiency of isolation of flavonoids from experimental conditions (temperature, pressure, extraction, time) was investigated. A maximal extraction yield of active components was obtained under optimal conditions: a temperature of $50{ }^{\circ} \mathrm{C}$, a pressure of $30 \mathrm{MPa}$ and an extraction time of $30 \mathrm{~min}$. The comparison of the contents of icariin, icariside II, epimedins A, B, C in the leaves of Epimedium Brevicornum extracts obtained by extraction with supercritical carbon dioxide and by ultrasound liquid extraction procedures was carried out by of liquid chromatography/mass spectrometry. The superiority of proposed method to traditional ultrasound liquid-liquid extraction in 2,5 times was demonstrated.

Keywords: Epimedium Brevicornum, extraction with supercritical carbon dioxide, icariin, icariside II, epimedins A, B, C, high performance liquid chromatography, mass spectrometry.

\section{References}

1. Flora SSSR. [Flora of the USSR]. Moscow, 1937, vol. 7, 718 p. (in Russ.).

2. Entsiklopedicheskii slovar' F.A. Brokgauza i I.A. Efrona: Bestsvetnik. [Collegiate Dictionary FA Brockhaus and IA Efron: Bestsvetnik]. St. Petersburg, 1980, vol. 3A, no. 6, 956 p. (in Russ.).

3. Editorial Committee of Pharmacopoeia of Ministry of Health PR China, The Pharmacopoeia of People's Republic of China. Beijing, 2010. Vol. 1.

4. Huang X., Zhu D.Y., Lou Y.J. Eur. J. Pharmacol., 2007, vol. 564, no. 1-3, pp. 26-36.

5. Humfrey C.D. Nat. Toxins., 1998, vol. 6, no. 2, pp. 51-59.

6. Felson D.T., Zhang Y., Hannan M.T., Kiel D.P., Wilson P.W., Anderson J.J. N. Engl. J. Med., 1993, vol. 329, no. 16, pp. 1141-1146.

7. $\quad$ Pan Y., Kong L., Xia X., Zhang W., Xia Z., Jiang F. Pharmacol. Biochem. Behav., 2005, vol. 82, no. 4, pp. 686-694.

8. Wu J., Du J., Xu C., Le J., Xu Y., Liu B., Dong B. Pharmacol. Biochem. Behav., 2011, vol. 98, no. 2, pp. $273-278$.

9. Ji H., Liu K., Li S.P., Gong X.J. J. Chin. Pharm. Univ., 2000, vol. 31, no. 3, pp. 222-225.

10. Meng F., Li Y.B., Xiong Z.L., Jiang Z.M., Li F.M. Phytomedicine, 2005, vol. 12, no. 3, pp. 189-193.

11. Ma A., Qi S., Xu D., Zhang X., Daloze P., Chen H. Transplantation, 2004, vol. 78, no. 6, pp. 831-838.

12. Cai M.L., Ji H., Li P., Wang M.Q. Chin. J. Nat. Med., 2004, vol. 2, no. 4, pp. 235-238.

13. Wang Y., Guo Z., Jin Y., Zhang X., Wang L., Xue X., Liang X. J. Pharm. and Biomed. Anal., 2010, vol. 51, no. 3, pp. 606-616.

14. Wu C.S., Guo B.L., Sheng Y.X., Zhang J.L. Chinese Chemical Letters, 2008, vol. 19, pp. 329-332.

15. Chen X.J., Ji H., Zhang Q.W., Tu P.F., Wang Y.T., Guo B.L., Li S.P. J. Pharm. and Biomed. Anal., 2008, vol. 46, no. 2, pp. 226-235.

16. Xu Y., Li Z., Yuan L., Zhang X., Lu D., Huang H., Wang Y. Chemistry and Biodiversity, 2013, vol. 10, no. 4, pp. 711-721.

17. Li Y., Duan J., Guo T., Xie W., Yan S., Li B., Zhou Y., Chen Y. J. Ethnopharmacol., 2009, vol. 124, no. 3, pp. $522-529$.

18. Mogiliuk V., Dobrovol'nyi A. Farmatsevticheskaia otrasl', 2015, vol. 48, no. 1, pp. 62-68. (in Russ.).

19. Pokrovskii O. Analitika, 2013, vol. 6, no. 13, pp. 22-27. (in Russ.).

20. Bogolitsyn K.G. Sverkhkriticheskie Fliuidy: Teoriia i Praktika, 2007, vol. 2, no. 1, pp. 16-27. (in Russ.).

21. Vodianik A.R., Shadrin A.Iu., Sinev M.Iu. Sverkhkriticheskie Fliuidy: Teoriia i Praktika, 2008, vol. 3, no. 2, pp. 58-69. (in Russ.).

22. Zhang H.-F., Yang T.-S., Li Z.-Z., Wang Y. Ultrasonics Sonochemistry, 2008, vol. 15, no. 4, pp. 376-385.

Received May 25, 2015

Revised July 15, 2015

\footnotetext{
${ }^{*}$ Corresponding author.
} 